\title{
RETÓRICA E HISTÓRIA NOS ENGENHOS DO PRESENTE: UMA CONVERSA COM JOÃO ADOLFO HANSEN
}

RHETORIC AND HISTORY IN THE PRESENT CRAFTSMANSHIP: A CONVERSATION WITH JOÃO ADOLFO HANSEN

João Adolfo Hansen

Otávio Augusto de Oliveira Moraes*
* otaviomoraesrg@gmail.com

Doutorando em Literatura pela UFMG, mestre em literatura pela PUC-MG.

O professor João Adolfo Hansen demanda pouca ou nenhuma apresentação. Conversar com ele é ter como interlocutor um dos maiores intelectuais do Brasil contemporâneo. No contexto do presente dossiê sua fala é particularmente preciosa por apontar uma direção interessante acerca do processo de leitura do objeto literário. Tal qual o professor nos mostra em obras de peso como A sátira e o engenho o ofício do historiador da literatura realiza-se na pesquisa das condições de criação e recepção do objeto artístico, em outras palavras, o tempo na forma e a forma no tempo.

Essa aposta de leitura desaloja algumas diretrizes estruturantes do processo de leitura da literatura brasileira,

principalmente no que se refere à primazia do elemento nacional. Fora desse esquadro romântico, cioso de bandeiras e raízes, o texto adentra nos mares turbulentos de uma tradição mais a mpla, a retórica poética.

Além desse horizonte de exposição e contextualização encontraremos, ao fim da entrevista, uma breve, mas essencial aposta acerca do literário, sua função, sua razão de ser enquanto parte da formação sensível no contemporâneo. Em sintonia com o professor, nós da Em Tese, bradamos o verso e a prosa enquanto plataforma humanizadora, luz contra as trevas que rodeiam o presente. Basta de apresentação, a palavra agora é do professor. 
COMO O SR. DEFINIRIA SUA FORMAÇÃO INTELECTUAL? FAÇO ESSA PERGUNTA NO INTUITO DE ARGUIR SOBRE QUAIS QUESTÕES E LEITURAS QUE TE DIRIGIRAM PARA O SEU CAMPO DE PESOUISA, NOTADAMENTE OS ESTUDOS ENVOLVENDO AS RETÓRICAS POÉTICAS.

$\mathrm{Na}$ Universidade, estudei Letras Anglo- Germânicas. Formado, fui professor de Latim no antigo curso Clássico. No final dos anos 1960, comecei na USP uma pós-graduação em Linguística e Semiótica, em que li o principal que havia sido feito nesses campos desde Saussure. Depois, início dos anos 1980, resolvi estudar Literatura Brasileira, fazendo um mestrado sobre Guimarães Rosa Como então tinha ficado chato ser moderno e eu não queria ser pós-moderno, resolvi estudar as letras luso-brasileiras dos séculos XVI, XVII e XVIII, fazendo meu doutorado sobre a poesia atribuída a Gregório de Matos e Guerra. O trabalho me remeteu necessaria mente para as retóricas antigas, gregas e latinas. Depois, interessado na historicidade das práticas simbólicas coloniais, relacionei o trabalho com a chamada história cultural. Esse campo, por sua vez, me fez interessar por questões relacionadas à historicidade dos processos de invenção, manutenção, apropriação, transmissão, consumo etc. das artes e da poesia e da prosa antigas. Assim, diria que meu trabalho vem sendo um cruzamento de teoria literária, história cultural, antropologia, e filologia.

PERCEBO EM SUAS OBRAS UMA ELABORADA CRÍTICA TANTO NO QUE TANGE A UMA PERSPECTIVA TELEOLÓGICA DE HISTÓRIA LITERÁRIA OUANTO EM RELAÇÃO A UMA APOSTA SINCRÔNICA DE LEITURA DO TEXTO LITERÁRIO, PORTANTO, PERGUNTO, OUAL SUA CONCEPÇÃO DE HISTÓRIA DA LITERATURA?

Meu trabalho com história literária tenta especificar os códigos bibliográficos e linguísticos das letras luso-brasileiras dos séculos XVI, XVII e XVIII e da literatura brasileira produzida a partir da Independência, em 1822. Quero dizer: meu trabalho evita as generalidades e generalizações teleológicas das histórias literárias brasileiras que, em geral, desde o século XIX são nacionalistas. Neste sentido, acredito que a história da literatura deve, de um lado, dar conta das condições materiais de produção das letras, estudando seus condicionamentos materiais e institucionais; ao mesmo tempo, ta mbém dar conta de seus códigos linguísticos, ou seja, da sua codificação retórico-poética; e, ainda, da sua recepção contemporânea e das cadeias das suas recepções. Em todos os casos, me parece básico especificar a particula ridade dos processos simbólicos de produção, publicação, recepção, apropriação e transmissão das obras. 
O PROCESSO DE MODERNIZAÇÃO DA LITERATURA MODIFICOU BASTANTE OS PRESSUPOSTOS DE CRIAÇÃO LITERÁRIA, TALVEZ O ELEMENTO MAIS MARCANTE TENHA SIDO NO CONCEITO DE AUTORIA, NÃO MAIS TÃO SUBSERVIENTE COM OS ANTIGOS E AGORA ATRELADO A NOÇÕES COMO A DE PROPRIEDADE INTELECTUAL E CONSEQUENTEMENTE DE PLÁGIO. EM MEIO A TANTA DIFERENÇA O OUE SR. APONTARIA ENOUANTO UMA PRESENÇA DA VELHA RETÓRICA DOS POETAS NAS LITERATURAS MODERNAS E CONTEMPORÂNEAS?

A questão da autoria é fundamental na produção e apropriação das letras antigas feitas até a Revolução Francesa e da literatura produzida nas sociedades burguesas pós-Revolução. Nas sociedades europeias anteriores à Revolução Francesa, existia o costume (consuetudo) mimético de inventar as obras segundo uma rígida codificação delas como gêneros prescritos e transmitidos de geração em geração pela- como diz Quintilianoinstituição retórica. A instituição predeterminava os conceitos de autoria, obra, público. Desde pelo menos os gregos do tempo de Aristóteles até o final do século XVIII, a instituição esteve a tiva e o conceito de autoria pressupunha a imitação/reprodução/emulação de uma autoridade que era ou tinha a auctoritas de determinado gênero. Digamos por exemplo que Homero e Virgílio eram as autoridades da poesia épica, assim como
Ovídio era autoridade da lírica etc. Com a Revolução Francesa e a nova sociedade burguesa, a autoria se tornou propriedade privada do bem cultural regulada por direitos que definiram e definem originalidade, plágio etc. Muito da velha retórica anterior à Revolução permaneceu- por exemplo, na conceituação de formas oratórias, historiográficas, poéticas ou dos diversos gêneros etc. Perma neceu, no entanto, redefinido, com novos valores de uso subordinados sempre ao valor de troca. Na sociedade pós-Revolução Francesa, toda a cultura é mercadoria.

NA PRODUÇÃO LITERÁRIA LUSÓFONA TEMOS EXEMPLOS DAS TEMÁTICAS ENVOLVENDO O PROCESSO DAS DESCOBERTAS E A EXPERIÊNCIA COLONIAL, OS ESCRITOS DE CAMÕES, GREGÓRIO DE MATTOS E ANTÔNIO VIEIRA SÃO UM EXEMPLO. TENDO EM VISTA ESSA QUESTÃO, COMO O SR. COMPREENDE O PROCESSO DE TRADUÇÃO, ADEQUAÇÃO DOS PARADIGMAS POÉTICO-RETÓRICOS EUROPEUS PARA OS ELEMENTOS NATIVOS NO QUE SE REFERE A LITERATURA COLONIAL? COMO ESSA LÓGICA DE CRIAÇÃO POÉTICA TROUXE PARA O SEU SEIO FIGURAS COMO A DOS AMERÍNDIOS E DOS AFRICANOS ESCRAVIZADOS?

Na colonização do Brasil, desde o século XVI, e a partir do início do século XVII, do Mara nhão e Grão Pará, uma questão enfrentada pela Coroa portuguesa e os governos 
coloniais foi a do controle e integração de populações indígenas e africanas. Como podemos ver nas coisas escritas por jesuítas dos séculos XVI e XVII, como Nóbrega, Anchieta, Vieira, os índios foram objeto de representação em discursos feitos antes de tudo para impor-lhes a assim chamada civilização católica. Suas culturas não foram consideradas, pois praticamente em todas as ocasiões foram classificadas como bárbaras, selvagens, gentias, ignorantes das verdades de Cristo e sua Igreja. Quanto aos negros escravos, pouco ou quase nada se fez por eles, pois eram definidos como peças, mercadorias etc. e não foram julgados coisa digna de representação. Num sermão feito para negros de um engenho baiano, Vieira diz que eles sofrem mais que Cristo no calvário, mas que tenham paciência, porque depois ga nharão um doce. Fernando Pessoa dizia que as religiões ensinam a confeitaria. Isso ta mbém depois da Independência, em 1822. Com poucas exceções, como a dos abolicionistas do século XIX, as populações africanas ficaram lá, na literatura brasileira do século XIX, como personagens de escolas de samba, eu diria, passando, passando...

POR FIM, DESVIANDO DA ROTA DAS QUESTÕES PRETÉRITAS, GOSTARIA DE PERGUNTAR PARA O SR. SOBRE SUA PERSPECTIVA NO OUE CONCERNE AO LETRAMENTO LITERÁRIO. O PRESENTE DOSSIÊ TEM COMO QUESTÃO A PRÓPRIA POSSIBILIDADE DE
COMPREENSÃO DO ENCONTRE ENTRE EXPERIÊNCIA HISTÓRICA E FORMA ARTÍSTICO-LITERÁRIA. QUESTÃO OUE PARA MIM PARECE URGENTE DADO OS ATAQUES E RELATIVIZAÇÕES OUE O CONHECIMENTO PRODUZIDO PELAS HUMANIDADES ANDA RECEBENDO. TENDO EM VISTA ESSE PANORAMA, PARA OUE SERVE O ENSINO DE LITERATURA?

Sobre sua última questão, digo o óbvio: o Presidente da República é um desclassificado asnal e o ministro da Educação um asno desclassificado. Jean Paul Sartre lembrou que a primeira coisa que pega fogo numa explosão nuclear é o papel em que o poeta escreveu o poema que critica a guerra nuclear. Quero dizer, a cultura é frágil frente à barbárie. Mas certamente o ensino de literatura pode ser útil, hoje, no Brasil, para evidenciar aos estudantes a historicidade da miséria e do sofrimento huma nos, quero dizer, evidenciar que não são naturais, mas produzidos historicamente, sempre, por inimigos do gênero humano. E, nesse sentido, ta mbém evidenciar que o poema, o conto, a novela, o romance ta mbém podem ser armas para destruir e reduzir a pó os bárbaros e a barbárie que produzem. Evidentemente, enquanto os bárbaros não são enforcados em praça pública, sem nenhum heroísmo, sem nenhuma pretensão redentora de salvar nada ou ninguém. 